\title{
Non-locking buttress plate in distal tibial metaphyseal fractures
}

\author{
Norman Lamichhane ${ }^{1}$, Bhogendra Bahadur KC ${ }^{1}$, Chandra Bahadur Mishra ${ }^{1}$, Sabita Dhakal ${ }^{2}$ \\ ${ }^{1}$ Department of Orthopedics, Pokhara Academy of Health Sciences, Pokhara, Western Regional \\ Hospital, Pokhara, Nepal \\ ${ }^{2}$ Nutrition and SBCC Officer, Suaahara, Nepal
}

\section{Correspondence}

Dr. Norman Lamichhane,

Department of Orthopedics,

Pokhara Academy of Health Sciences,

Pokhara, Nepal

Western Regional Hospital

Email: norman3082@gmail.com

Article received : 9th June 2018

Article accepted :4th Oct. 2018

\begin{abstract}
:
Background: Treatment of distal tibial metaphyseal fractures is often challenging and no single technique has been unanimously advocated. Open reduction and internal fixation with plates and screws allows better restoration of anatomical alignment but with more soft tissue complication. Simultaneous fixation of the fibula is not universally carried out. This study aims at evaluation of the outcome of plating technique and the effect of fixation of fibula fracture in treatment of distal tibial metaphyseal fractures.
\end{abstract}

Material and methods: Thirty-one cases (14 cases in Group A with concomitant distal fibula fracture and 17 cases in Group B without distal fibula fracture) were analyzed retrospectively for the mean duration of full weight bearing, mean union time and complications, and compared.

Results: The mean time for full weight bearing and radiological union in our study was 14.2 weeks (15.9 in Group A and 13.1 in Group B) and 23.8 weeks (26.6 in Group A and 21.5 in Group B) respectively. $16.1 \%$ of cases had post-operative complications including one case of deep infection and malalignment of 6 degree varus (following delayed union) was seen in one case of Group A. Range of motion (ROM) at ankle was not problem in any of the cases except the one delayed union which had 5 degrees of dorsiflexion and 15 degrees of plantiflexion.

Conclusion: Open reduction and internal fixation with plate and screws in distal tibial metaphyseal fracture is more economic means of treatment modality with comparable incidence of post-union malalignment and union time,though more soft tissue complications compared to other modalities. Fixation of fibula fracture aids in reducing the incidence of malalignment.

Key words: Distal tibial metaphyseal fracture, Open reduction and internal fixation, Non-locking buttress plate.

\section{INTRODUCTION}

The treatment of distal tibia fracture is often challenging due to thin soft tissue coverage and their proximity to ankle. ${ }^{1,2}$ Good reduction is difficult to achieve by nonoperative or nailing method in this type of fracture. ${ }^{3}$ Casting technique is associated with stiffness of ankle due to prolonged immobilization and loss of reduction isn't uncommon. ${ }^{4,5}$ Conventional intramedullary nailing has been often found with loss of reduction, non-union and increased post-operative pain due to motion at fracture site. ${ }^{6}$ Open reduction and internal fixation with anatomical plate have advantage of better anatomical alignment than intramedullary nailing but with more wound complications. ${ }^{7}$ This study aims at evaluating the full weight bearing and radiological union time in patient with distal tibial metaphyseal fracture after treatment with non-locking buttress plate, association of distal fibular fracture and its plating on it, and complications associated with distal tibial plating. 


\section{MATERIAL AND METHODS}

During time of two years from March 2016, after excluding 5 patients that were lost to follow up, 31 skeletally matured cases of distal tibia fracture extending within $5 \mathrm{~cm}$ of articular surface presenting to Kaski Model Hospital, Pokhara, were included in study. The study design is retrospective analytical study. Fourteen of those cases were associated with distal fibula fracture (Group A) and remaining were isolated distal tibia fracture or associated with proximal fibula fracture (Group B). Fractures extending to articular surface, compound fractures, previous history of same bone fracture, pathologic fractures and patients with polytrauma were excluded from the study.

Ethical clearance was taken from ethical review board. Demographic profile (age and sex), mechanism of injury and fracture pattern was noted. After obtaining informed consent from the patients, patients were taken to operative room. Operative procedure was carried out under spinal anesthesia. Most of the fractures were fixed within 24 hours and operative procedure was delayed up to 1 week in the cases who had blister at operative site. Fibula was fixed first, with semi-tubular plate and screws in the cases who had associated distal fibula fracture. Tibia was fixed with distal tibial non-locking contoured plate through anteromedial approach securing long saphenous vein in all cases. Dissection was carried out cautiously with care to soft tissue and without stripping periosteum. Limb was immobilized in short leg posterior slab for two weeks, after which suture was taken out and active ankle mobilization started. Non-weight bearing crutch walking was started following day after surgery. All patient were assessed clinically (full weight bearing if Visual Analogue Scale $<3$ and return to previous state of employment) and radiologically at 6 weeks, 3 months and 6 weekly afterward. Radiological assessment was done with standard anteroposterior and lateral $x$-rays. Fracture was considered united if radiology showed bridging of at least three cortices with matured callus. The clinical and radiological outcome was compared between two groups. Complications, and the interventions to manage them were noted.

Data were analyzed using Statistical Package for Social Sciences (SPSS version 22). Independent t-test was used to evaluate the significance of the compared data. P-value of less than 0.05 was considered significant.

\section{RESULT}

Out of 31 patients, 14 patients were with both distal tibia and fibula fracture (Group A) and 17 were with distal tibia,or distal tibia and proximal fibula (6 cases) fractures (Group B). The mean age of the patient in Group A was 42.4 years and that in Group B was 39.5 years. The difference in age distribution in two group was statistically insignificant ( $p$ value $>0.05$ ). Out of 14 cases in Group A, 11 cases were with comminuted fracture of tibia and rest had spiral pattern. The fracture pattern in most of the cases of Group B was spiral type (13 out of 17), 2 cases had long oblique pattern and 2 had comminution. All of those 14 cases had history of high velocity trauma (motor vehicle accident) in Group A. Out of 17 cases in other group $B$, only 6 cases had history of high velocity trauma (Figure 1).

Figure 1. Type of fracture and velocity of trauma

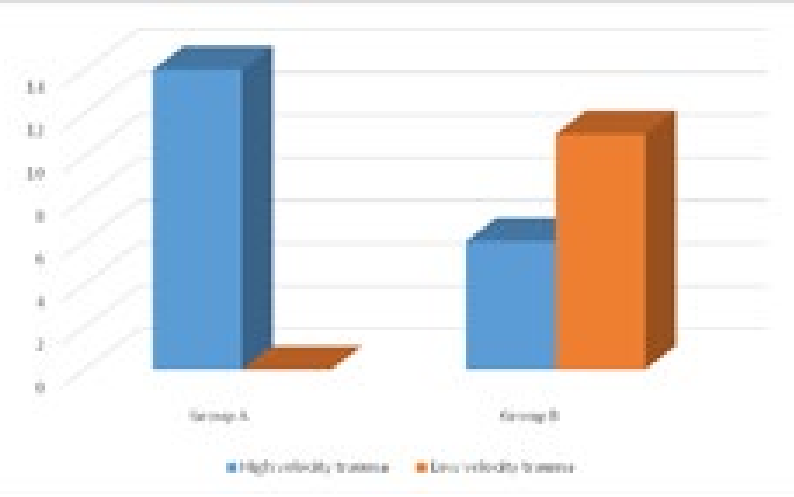

The mean time for full weight bearing in patients of group A was 15.9 weeks and mean time for radiological union was 26.6 weeks, whereas in group B mean time for full weight bearing and mean time for union was 13.1 weeks and 21.5 weeks respectively. The difference of these times between two groups was statistically insignificant ( $p$ value $>0.05$ )

Figure 2: Preoperative, post-operative and post-union radiography of avobe and Group B pacients below.

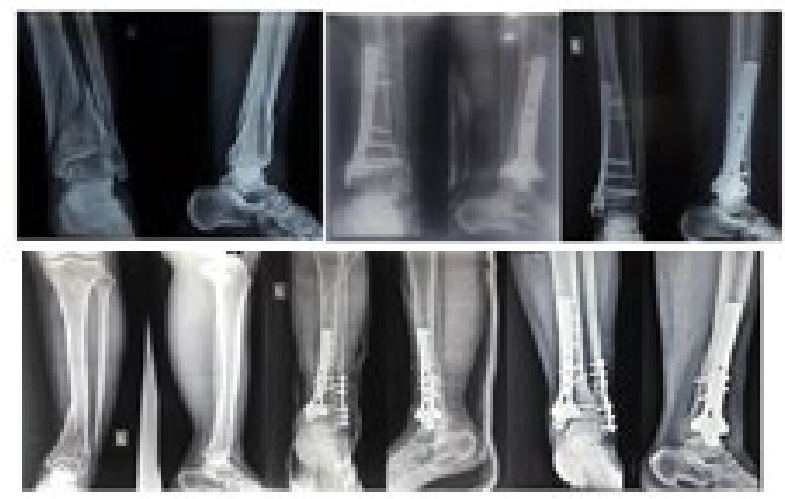

One patient in Group A showed delayed union at 9 months and autologous iliac crest grafting was done. 
The fracture united completely at 12 months in that patient. One patient in Group A had deep infection leading to implant exposure which was treated with soleus flap after controlling infection. Minor complications like skin blisters (2 in group $A$ and 1 in Group B) and superficial wound infection (one in Group A) were seen which subsided with time without any intervention and oral antibiotic combined with daily dressing respectively. One of the case in Group A had reduced ROM ( 5 degrees dorsiflexion and 15 degreees plantiflexion) at the end. No significant secondary malalignment (varus/valgus deformity, anterior and posterior angulation were less than 5 degrees) was seen except in the case with delayed union, in which 6 degrees of valgus angulation was present.

\section{DISCUSSION}

Distal tibial fracture usually presents with severe soft tissue problem due to high energy trauma and scanty blood circulation. Complications like wound dehiscence, soft tissue infection, delayed union and non-union are common problems if soft tissue status is ignored. ${ }^{8}$ Mostly, considerable hardware and surgical dissection is required while fixing the comminuted metaphyseal fragment to the diaphysis in an attempt to restore proper axial alignment. ${ }^{9}$

Adequate interfragmentary motion and gap size are major mechanical factors that influence the union. ${ }^{10}$ The simultaneous presence of low interfragmentary axial movement and high interfragmentary shear strain is predictive of a poor outcome which is seen with intramedullary nailing in distal tibia fracture..$^{11,12}$ The degree of weight bearing is associated with pain and analgesic medication after surgery. ${ }^{13,} 14$ So the time to full weight bearing with minimal or no pain was considered a parameter towards fracture healing in our cases.

The mean time for full weight bearing and radiological union in our study was 14.2 weeks and 23.8 weeks respectively. They are compared with other studies in Table 1 . In a study by Redfern et al. ${ }^{15}$, where fracture was treated with MIPPO (Minimally Invasive Percutaneous Plate Osteosynthesis), the mean time for full weight bearing and radiological union was 12 weeks and 23 weeks respectively similar to other studies. , $^{8,17}$ Though the time for full weight bearing and radiological union in our cases were little more than in the studies where MIPPO, IM nailing and ASLS was done, the time is comparable. So non- locking buttress plate in fixation of the distal tibial metaphyseal fracture need not to be abandoned for these factors, but has an advantage of low cost and non-requirement of $\mathrm{C}$-arm and should be considered in some patitents. The difference in time for full weight bearing and radiological union between two groups of our study was statistically insignificant, though the differences were more than 2 weeks and 5 weeks respectively. The presence of fibular fracture doesn't lead to significant difference in union time.

The mean time for full weight bearing and radiological union was more in Group A than in group B. The increased time for both parameters in Group A was because most of the patient in this group had history of high velocity trauma which led to more soft tissue damage leading to delayed union.

Table 1: Mean time of full weight bearing and radiological union in different studies

\begin{tabular}{|c|c|c|c|c|}
\hline Study & \multicolumn{2}{|c|}{ Гype of fixation used } & $\begin{array}{l}\text { Mean time for full } \\
\text { weight bearing }\end{array}$ & $\begin{array}{l}\text { Mean time for } \\
\text { radiological union }\end{array}$ \\
\hline \multirow{2}{*}{\multicolumn{2}{|c|}{ Yang et al. ${ }^{18}$}} & Plating & & 27.8 \\
\hline & & IM nailing & & 22.6 \\
\hline \multicolumn{2}{|c|}{ Redfern et al. ${ }^{15}$} & MIPPO & 12 & 23 \\
\hline \multicolumn{2}{|c|}{ Höntzsch et al. ${ }^{19}$} & ASLS & 10.6 & \\
\hline \multicolumn{2}{|l|}{ Nork et al. ${ }^{20}$} & IM nailing & & 23.5 \\
\hline \multirow[t]{3}{*}{ Our study } & \multicolumn{4}{|c|}{ Non-locking buttress plate } \\
\hline & \multicolumn{2}{|c|}{ Isolated tibia fracture } & 13.1 & 21.5 \\
\hline & \multicolumn{2}{|c|}{ Both bone fracture } & 15.9 & 26.6 \\
\hline
\end{tabular}

The range of motion (ROM) wasn't problem in any of the cases in Group B. One of the cases in Group $A$ had reduced ROM ( 5 degrees dorsiflexion and 15 degreees plantiflexion) at the end. The case was the one which had delayed union. ROM wasn't issue in other cases as ROM exercise was started at 2 weeks with slab removal.

Thirteen patients $(23 \%)$ with IM nailing and 4 patients $(8 \%)$ with plateshad had secondary malalignment of 5 degrees or more in a study by Vallier et al. ${ }^{2}$ but only one case $(3.2 \%)$ was reported in our study, compared to $5 \%$ to $23 \%$ in other published studies. ${ }^{2}$, ${ }^{20,}{ }^{21}$ The case of malalignment was the one that had delayed union and had 6 degrees of valgus deformity. IM nailing is associated with more malalignment than plating. ${ }^{2}$ Fourteen patients (18\%) in ASLS group and 7 patients (11\%) in IM nailing group in their study2 had post-operative complications, compared to 5 (16.1\%) in our cases. One of our case in Group A had deep 
infection leading to implant exposure, who underwent flap coverage after controlling infection and eventually united at 40 weeks. Both bone fracture has more incidence of pos-operative complications than isolated tibia. IM nailing has advantage of lower chance of deep infection as compared to plating.

Thirty six percentage of cases had associated fibula fracture in a study by Höntzsch et al. ${ }^{19}$, compared to $45 \%$ in our study. Eighty five percent of patients with malalignment after nailing didn't have fibula fixation in a study by Valiier et al. ${ }^{2}$ Fibula fixation aids in reduction of tibia intraoperatively in distal both bone fracture reducing the complications of malalignment. Less duration of operation, early restoration of motion, and reduced wound problems are the advantage seen with IM nailing, whereas plate and screws can restore the alignment of the bone better. ${ }^{7}$

Distal tibial plate is pre-contoured to the anatomy of the distal tibia, so the fracture fragments are uninterrupted during fixation. ${ }^{17}$ Furthermore, the use of the nonlocking plate allows placement of the lag screw through the plate itself. Though short leg posterior slab was applied for 2 weeks post-operatively, ankle stiffness wasn't problem in our cases. Anterior knee pain isn't the problem in plating as seen with IM nailing. ${ }^{7}$
The retrospective design of the study and absence of control group with other modalities of treatments (IMIL nailing and MIPPO) are limitations of our study. Furthermore, more number of cases could have strengthened the findings of our study.

\section{CONCLUSION}

Open reduction and internal fixation with non-locking distal tibial buttress plate is more economic means of fixation in distal tibia fracture that does not require $\mathrm{C}$-arm and has comparable results (no huge gap in weight bearing and union time), though inferior in postoperative soft tissue complications, with that of MIPPO and IM nailing. Meticulous soft tissue dissection along with minimal incision helps in reduction of postoperative complications. This technique is better suited in the areas where limited resource (non-availability of $\mathrm{C}$-arm) and non-affording patient to better technique like MIPPO. Fixation of fibula fracture often helps in restoration of the alignment per-operatively leading to reduced incidence of malalignment. However, both bone fracture is associated with more soft tissue complications post-operatively than isolated tibia fracture.

\section{REFERENCES}

1. Krackhardt T, Dilger J, Flesch I, Höntzsch D, Eingartner C, Weise K. Fractures of the distal tibia treated with closed reduction and minimally invasive plating. Archives of orthopaedic and trauma surgery. 2005;125(2):87-94.

2. Vallier HA, Cureton BA, Patterson BM. Randomized, prospective comparison of plate versus intramedullary nail fixation for distal tibia shaft fractures. Journal of orthopaedic trauma. 2011;25(12):736-41.

3. Manninen M, Lindahl J, Kankare J, Hirvensalo E. Lateral approach for fixation of the fractures of the distal tibia. Outcome of 20 patients. Archives of orthopaedic and trauma surgery. 2007;127(5):349-53.

4. Digby JM, Holloway GM, Webb JK. A study of function after tibial cast bracing. Injury. 1983;14(5):432-9.

5. Sarmiento A, Sharpe FE, Ebramzadeh E, Normand P, Shankwiler J. Factors influencing the outcome of closed tibial fractures treated with functional bracing. Clinical orthopaedics and related research. 1995(315):8-24.

6. Lang GJ, Cohen BE, Bosse MJ, Kellam JF. Proximal third tibial shaft fractures. Should they be nailed? Clinical orthopaedics and related research. 1995(315):64-74.

7. Im G-I, Tae S-K. Distal metaphyseal fractures of tibia: a prospective randomized trial of closed reduction and intramedullary nail versus open reduction and plate and screws fixation. Journal of Trauma and Acute Care Surgery. 2005;59(5):1219-23.

8. Aksekili M, Celik I, Arslan AK, Kalkan T, Uğurlu M. The results of minimally invasive percutaneous plate osteosynthesis (MIPPO) in distal and diaphyseal tibial fractures. Acta orthopaedica et traumatologica turcica. 2012;46(3):161-7.

9. Francois J, Vandeputte G, Verheyden F, Nelen G. Percutaneous plate fixation of fractures of the distal tibia. Acta orthopaedica belgica. 2004;70(2):148-54.

10. Kaspar K, Schell H, Seebeck P, Thompson MS, Schütz M, Haas N, et al. Angle stable locking reduces interfragmentary movements and promotes healing after unreamed nailing: Study of a displaced osteotomy model in sheep tibiae. JBJS. 2005;87(9):2028-37. 
11. Augat P, Burger J, Schorlemmer S, Henke T, Peraus M, Claes L. Shear movement at the fracture site delays healing in a diaphyseal fracture model. Journal of orthopaedic research. 2003;21(6):1011-7.

12. Park S-H, O'connor K, McKellop H, Sarmiento A. The influence of active shear or compressive motion on fracture-healing. JBJS. 1998;80(6):868-78.

13. Joslin C, Eastaugh-Waring S, Hardy J, Cunningham JL. Weight bearing after tibial fracture as a guide to healing. Clinical Biomechanics. 2008;23(3):329-33.

14. Hazarika S, Chakravarthy J, Cooper J. Minimally invasive locking plate osteosynthesis for fractures of the distal tibia-results in 20 patients. Injury. 2006;37(9):877-87.

15. Redfern D, Syed S, Davies S. Fractures of the distal tibia: minimally invasive plate osteosynthesis. Injury. 2004;35(6):615-20.

16. Cheng W, LiY, Manyi W. Comparison study of two surgical options for distal tibia fracture-minimally invasive plate osteosynthesis vs. open reduction and internal fixation. International orthopaedics. 2011;35(5):737-42.

17. Bahari S, Lenehan B, Khan H, McElwain JP. Minimally invasive percutaneous plate fixation of distal tibia fractures. Acta Orthopædica Belgica. 2007;73(5):635.

18. Yang S-W, Tzeng H-M, Chou Y-J, Teng H-P, Liu H-H, Wong C-Y. Treatment of distal tibial metaphyseal fractures: plating versus shortened intramedullary nailing. Injury. 2006;37(6):531-5.

19. Höntzsch D, Schaser K-D, Hofmann GO, Pohlemann T, Hem ES, Rothenbach E, et al. Evaluation of the effectiveness of the angular stable locking system in patients with distal tibial fractures treated with intramedullary nailing: a multicenter randomized controlled trial. JBJS. 2014;96(22):1889-97.

20. Nork SE, Schwartz AK, Agel J, Holt SK, Schrick JL, Winquist RA. Intramedullary nailing of distal metaphyseal tibial fractures. JBJS. 2005;87(6):1213-21.

21. Zelle BA, Bhandari M, Espiritu M, Koval KJ, Zlowodzki M, Group E-BOTW. Treatment of distal tibia fractures without articular involvement: a systematic review of 1125 fractures. Journal of orthopaedic trauma.

2006;20(1):76-9. 